CLINICAL STUDY

\title{
Atherosclerotic risk factors and complications in patients with non-functioning adrenal adenomas treated with or without adrenalectomy: a long-term follow-up study
}

\author{
Márta Sereg $^{1}$, Ágnes Szappanos ${ }^{1}$, Judit Tóke ${ }^{1}$, Kinga Karlinger ${ }^{2}$, Karolina Feldman ${ }^{1}$, Éva Kaszper ${ }^{1}$, Ibolya Varga ${ }^{1,3}$, \\ Edit Gláz ${ }^{1}$, Károly Rácz ${ }^{1}$ and Miklós Tóth ${ }^{1}$ \\ ${ }^{1}$ 2nd Department of Medicine, Faculty of Medicine, Semmelweis University, Szentkirályi u. 46, Budapest H-1088, Hungary, ${ }^{2}$ Department of Diagnostic \\ Radiology and Oncotherapy, Faculty of Medicine, Semmelweis University, Budapest, Hungary and ${ }^{3}$ Molecular Medicine Research Group, Semmelweis \\ University and the Hungarian Academy of Sciences, Budapest, Hungary \\ (Correspondence should be addressed to M Tóth; Email: totmik@bel2.sote.hu)
}

\begin{abstract}
Objective: Despite the increased prevalences of hypertension, type 2 diabetes mellitus (T2DM), hyperlipidemy, and obesity in patients with non-functioning adrenal adenomas (NFAAs), there is a paucity of data on long-term atherosclerotic morbidity as well as the long-term cardiovascular effects of adrenalectomy in these patients.

Design, patients, and methods: This retrospective study includes the results of baseline and follow-up investigations of 125 patients ( 29 males and 96 females; mean age 60.1 years) with NFAAs referred for endocrine evaluation between 1990 and 2001. Of the 125 patients, 47 underwent unilateral adrenalectomy, while 78 patients were followed conservatively. These patients were reinvestigated after a mean follow-up time of 9.1 (5-16) years in 2006, with special emphasis on laboratory and other atherosclerotic risk factors (ARF), vascular events, and interventions.

Results: The prevalences of hypertension, impaired glucose tolerance or T2DM, hyperlipidemy, and obesity were $82,43,58$, and $50 \%$, and $89,58,82$, and $50 \%$ at baseline and follow-up, respectively. None of the investigated ARF prevalences were different between patients treated and not treated with adrenalectomy, and between patients with and without subclinical Cushing's syndrome. The prevalences of angina pectoris, acute myocardial infarction, coronary, and peripheral arterial interventions or cerebrovascular stroke did not differ significantly between patients treated and not treated with adrenalectomy.

Conclusion: Our study confirms previous investigations reporting markedly increased prevalences of various ARF in patients with NFAAs. Adrenalectomy performed in these patients failed to decrease the prevalence of ARF and atherosclerotic morbidity.
\end{abstract}

European Journal of Endocrinology 160 647-655

\section{Introduction}

Adrenal incidentalomas are mostly (in 70-80\% of cases) non-functioning adrenal adenomas (NFAAs) which do not cause classical clinical signs and symptoms of hormone excess syndromes (1-4). However, $5-47 \%$ of the NFAAs show mild cortisol oversecretion without symptoms of Cushing's syndrome referred to as subclinical autonomous glucocorticoid hypersecretion or subclinical Cushing's syndrome. The prevalence of subclinical Cushing's syndrome among patients with NFAAs depends on the criteria used to define it. The lack of a golden standard, however, makes the diagnosis of subclinical hypercortisolism uncertain (3, 5-14).

Several lines of evidence suggest that in addition to cortisol-producing adrenal adenomas causing overt Cushing's syndrome, NFAAs are also associated with an increased atherosclerotic risk (15). The increased prevalence of various biochemical disturbances and accompanying diseases such as type 2 diabetes (T2DM) and hypertension is thought to be resulted from a mild glucocorticoid overactivity of these tumors. Unfortunately, this mild glucocorticoid excess cannot be always detected with a sufficient degree of sensitivity and specificity.

Autonomous cortisol hypersecretion may cause a variety of metabolic derangements and disorders, such as arterial hypertension, impaired glucose tolerance (IGT) and T2DM, hypercholesterolemia, hypertrigliceridemia, hyperuricemia, and obesity. An increased prevalence of these metabolic disorders has been reported in patients with subclinical Cushing's syndrome (16-24). Mild autonomous cortisol hypersecretion caused by seemingly silent adrenal adenomas has 
also been suggested as a new possible cause of metabolic syndrome $(16,25,26)$.

These metabolic disorders are well-known risk factors for atherosclerosis. It was shown that surgical treatment of endogenous hypercortisolism reduces mortality and morbidity $(18,21,27,28)$. However, there is a lack of long-term follow-up studies that investigate the issue of whether patients with incidentally discovered adrenal adenomas, either hormonally inactive or only moderately active, could benefit from adrenalectomy in terms of cardiovascular morbidity and mortality.

The aim of our present study was to investigate the prevalence of various atherosclerotic risk factors (ARF), both at baseline and at least 5 years later in patients with NFAAs. Further aim of this work was to study whether adrenal surgical intervention could have an impact on atherosclerotic morbidity and mortality of these patients.

\section{Subjects and methods}

The results of clinical, laboratory, and imaging investigations of patients with NFAAs referred for evaluation to our endocrine unit at Semmelweis University between 1990 and 2001 were retrospectively analyzed. The initial imaging modalities were usually ultrasonography and computed tomography. All patients underwent complete clinical, radiological, and hormonal evaluation during their baseline investigation. Serum cortisol concentrations were measured from blood samples collected at 0800 and $2400 \mathrm{~h}$, as well as after a low-dose $(1 \mathrm{mg})$ dexamethasone suppression test. Hormonal investigations also included the measurements of serum DHEA sulfate, aldosterone, 17-hydroxyprogesterone, testosterone, plasma ACTH concentration, and plasma renin activity. The 24-h urine collection was performed for the determination of vanillylmandelic acid excretion. Nuclear magnetic resonance imaging and cholesterol- or MIBG-scintigraphy were performed if indicated. In case of a suspicion for primary aldosteronism, saline suppression test and, in some patients, selective adrenal vein sampling for aldosterone and cortisol measurements were also performed.

Based on the results of these investigations, patients with classic hormone excess syndrome (primary hyperaldosteronism, adrenal Cushing's syndrome, and pheochromocytoma) and those with a tumor greater than $4 \mathrm{~cm}$ commonly underwent adrenal surgery. Adrenal surgery was also performed if the possibility of adrenal malignancy persisted even after repeated laboratory and imaging investigations. Adrenal malignancy was frequently suspected in patients with tumors greater than $4 \mathrm{~cm}$ with irregular contours and a CT attenuation value greater than $10 \mathrm{HU}$, or with inhomogenities suggesting intratumoral necrosis or hemorrhage. However, several patients with a tumor diameter smaller than $4 \mathrm{~cm}$ were subjected to adrenalectomy when CT or MRI morphology not unequivocally suggested a benign lipid-rich adrenal lesion. In some other cases with a tumor size smaller than $4 \mathrm{~cm}$, the patient expressed a strong preference for surgical intervention, especially when laparoscopic operation for symptomatic gallbladder stones offered the choice of simultaneous laparoscopic adrenalectomy.

In 2006, 171 patients diagnosed with NFAAs between 1990 and 2001 were invited in letter for an ambulatory follow-up medical investigation. Of the 171 invited patients, 113 patients were re-examined using our re-investigation protocol. Patients were instructed to present all of the medical documents including the results of all laboratory and imaging examinations and hospitalization records. Our re-investigation protocol consisted of a detailed medical and drug history, physical examination including blood pressure, body weight, and height measurements, as well as detailed laboratory and basal hormone investigations. The protocol was approved by the local ethics committee. All of the patients with an abdominal CT performed 2 or more years earlier underwent adrenal computed tomography. The CT diagnosis of adrenal adenoma was based on the following criteria: mass size usually lower than $4 \mathrm{~cm}$, homogeneity, regular well-defined margins, and attenuation values less than $10 \mathrm{HU}$ on unenhanced $\mathrm{CT}$ and, when using a 10- to 15-min delayed enhanced CT, a threshold value of $50-60 \%$ of the initial enhancement (3). In addition, all of the relevant medical documents of 12 further patients (four patients treated and eight not treated with adrenalectomy), who could not attend our clinic for the follow-up examination, were obtained either from the patients or their relatives, and the data were subsequently verified during a consultation with their family doctors. The reasons for the non-attendance were hemiparesis caused by ischemic cerebrovascular stroke (one patient), severe chronic obstructive pulmonary disease (one patient), and severe ischemic heart disease (one patient), deaths from malignant non-adrenal tumors (two patients), from severe chronic obstructive pulmonary disease (one patient), from cardiovascular disease (five patients), and from unknown cause (one patient).

Of the 125 patients with NFAAs having follow-up examinations or presenting follow-up data, 47 patients underwent unilateral adrenalectomy between 1990 and 2001. Histological examination revealed a benign adrenocortical adenoma in each patient. The remaining 78 patients were treated conservatively, without adrenalectomy. Of the 46 patients whose follow-up data were not available, 15 patients had unilateral adrenalectomy between 1990 and 2001 according to earlier records. Baseline plasma cortisol concentrations at 0800, $2400 \mathrm{~h}$ and after low-dose dexamethasone test as well as tumor diameters were not different between patients who were and were not available for follow-up investigations. 
At the ambulatory follow-up visit, all of the 113 patients underwent fasting blood sampling for detailed laboratory measurements including complete blood cell count, hepatic and kidney functions, detailed lipoprotein, and hormone measurements. Patients on antihyperlipidemic medications and those who had total cholesterol greater than $5.2 \mathrm{mmol} / \mathrm{l}$, low density lipoprotein cholesterol greater than $2.6 \mathrm{mmol} / \mathrm{l}$ or triglycerides greater than $1.7 \mathrm{mmol} / \mathrm{l}$ were considered to have hyperlipidemia.

Patients with a previous definitive diagnosis of diabetes mellitus and those on antidiabetic medications were regarded as diabetic. All of the other patients underwent an oral glucose tolerance test (OGTT, $75 \mathrm{~g}$ glucose diluted in $250 \mathrm{ml}$ water). IGT and diabetes mellitus were defined according to the criteria of WHO (1999) (29). Diabetes mellitus was diagnosed when fasting plasma glucose exceeded $7.0 \mathrm{mmol} / \mathrm{l}$ or the glucose response after OGTT at $120 \mathrm{~min}$ was $11.1 \mathrm{mmol} / \mathrm{l}$ or greater. IGT was diagnosed when blood glucose levels at $120 \mathrm{~min}$ after OGTT were between 7.8 and $11.0 \mathrm{mmol} / \mathrm{l}$. Laboratory results obtained during the baseline in-hospital examination including fasting, postprandial or after OGTT plasma glucose concentrations were reviewed and each patient was reclassified as normal, having IGT or diabetes mellitus according to the 1999 WHO criteria (29). Patients regularly taking antihypertensive medications and patients repeatedly having blood pressure greater than 140/90 $\mathrm{mmHg}$ were considered to have hypertension (30).

Subclinical Cushing's syndrome was diagnosed in patients without overt clinical signs and symptoms of Cushing's disease with at least one of the following two criteria: i) midnight serum cortisol concentration greater than $5 \mu \mathrm{g} / \mathrm{dl}$ and ii) plasma cortisol concentration greater than $3.6 \mu \mathrm{g} / \mathrm{dl}$ after low-dose dexamethasone suppression test.

For the comparison of the prevalences of hypertension and diabetes mellitus in our patients to that of the general Hungarian population, a large, communitybased sample obtained in primary care facilities in four Hungarian counties was used. This database was shown to broadly represent the Hungarian general population, as virtually all Hungarian inhabitants are registered at family doctors (31).

\section{Statistical analysis}

Statistical analysis was performed using Statistica package (version 7.0, Statsoft Inc., Tulsa, Oklahoma, USA). A value of $P<0.05$ was considered to be significant. The relative frequencies of each atherosclerotic event and disease recorded at follow-up were compared between patient groups treated with and without adrenalectomy, using chi-square analysis and Fisher's exact test. The frequencies of metabolic disorders and hormonal parameters were compared with $t$-test and Mann-Whitney U-test.

\section{Results}

The main clinical characteristics of the 125 patients with NFAAs, who participated in the follow-up examination or presented follow-up data are summarized in Table 1. There were no statistically significant differences in age and sex ratios between patients treated and not treated with adrenalectomy. The median follow-up time for all patients was 9.1 years (range, 5-16 years), and patients with and without adrenalectomy had similar follow-up times (Table 1). However, the baseline diameter of adrenal tumors of patients who underwent adrenalectomy was significantly larger when compared with that found at baseline in patients without subsequent adrenalectomy.

At the baseline endocrine investigation, plasma cortisol concentrations at 0800 and $2400 \mathrm{~h}$, as well as after a low-dose dexamethasone test failed to show differences between patients subsequently treated and not treated with adrenalectomy (Table 2).

Table 3 shows the prevalences of various ARF in patients with NFAAs both at baseline and at the followup. The prevalences of risk factors and laboratory data at the time of follow-up were compared with the baseline data, and these parameters were also compared in the two groups of patients treated and not treated with adrenalectomy. As shown in Table 3, the prevalences of hypertension at baseline were very high in both groups (86 and $80 \%$ in patients with and without subsequent adrenalectomy, respectively), and this high prevalence persisted at the time of follow-up

Table 1 Main clinical characteristics of the 125 patients with non-functioning adrenocortical adenomas who participated in the follow-up examination or presented follow-up data.

\begin{tabular}{lllll}
\hline & All patients & $\begin{array}{l}\text { Patients with } \\
\text { adrenalectomy }\end{array}$ & $\begin{array}{l}\text { Patients without } \\
\text { adrenalectomy }\end{array}$ & $\begin{array}{l}\text { Difference between } \\
\text { patients with and } \\
\text { without adrenalectomy }\end{array}$ \\
\hline Number of patients & 125 & 47 & 78 & $\mathrm{NS}$ \\
Male/female & $29 / 96$ & $8 / 39$ & $21 / 57$ & $\mathrm{NS}$ \\
Age of patients at baseline, year & $51.8 \pm 9.9$ & $50.6 \pm 7.2$ & $52.5 \pm 11.2$ & $\mathrm{NS}$ \\
Age of patients at follow-up, year & $60.9 \pm 9.9$ & $60.0 \pm 7.1$ & $61.4 \pm 11.3$ & $P<0.0001$ \\
Baseline tumor diameter, mm & $26.0 \pm 11.9$ & $33.4 \pm 10.8$ & $21.5 \pm 10.2$ & $\mathrm{NS}$ \\
Follow-up time, year & $9.1 \pm 3.1$ & $9.4 \pm 3.6$ & $8.8 \pm 2.8$ & \\
\hline
\end{tabular}

Data are given as means and SDs. NS, not significant. 
Table 2 Baseline hormonal findings in patients with non-functioning adrenocortical adenomas subsequently treated and not treated with adrenalectomy.

\begin{tabular}{lccc}
\hline & $\begin{array}{c}\text { Patients with } \\
\text { subsequent adrenalectomy }\end{array}$ & $\begin{array}{c}\text { Patients without } \\
\text { subsequent adrenalectomy }\end{array}$ & $\begin{array}{c}\text { Difference between } \\
\text { patients with and without } \\
\text { adrenalectomy }\end{array}$ \\
\hline Midnight plasma cortisol $(\mu \mathrm{g} / \mathrm{dl})$ & $2.6 \pm 1.7$ & $3.1 \pm 2.6$ & $\mathrm{NS}$ \\
Morning plasma cortisol $(\mu \mathrm{g} / \mathrm{dl})$ & $9.8 \pm 5.8$ & $10.9 \pm 4.6$ & $\mathrm{NS}$ \\
Plasma cortisol after low-dose & $2.2 \pm 2.4$ & $1.9 \pm 0.7$ & $\mathrm{NS}$ \\
DXM $(\mu \mathrm{g} / \mathrm{dl})$ & $\mathrm{kg} / \mathrm{ml})$ & $23.3 \pm 12.9$ & $\mathrm{NS}$ \\
Plasma ACTH $(\mathrm{pg} / \mathrm{m})$ & $33.9 \pm 18.5$ & \\
\hline
\end{tabular}

Data are given as means and SDs. NS, not significant.

without significant differences between the two groups. Patients undergoing adrenalectomy were slightly more obese at baseline than those who were not treated with adrenalectomy, but the difference was not statistically significant. At the time of follow-up, the BMI was slightly increased in both groups without any significant differences between the two groups. When compared with baseline, the prevalence of hyperlipidemia and the number of patients treated with lipidlowering drugs increased significantly at the time of follow-up in the two groups of patients with and without adrenalectomy. Plasma total cholesterol concentrations in both groups showed a significant decrease at the time of follow-up when compared with those measured at baseline. There were no statistically significant differences in the frequency of usage of lipidlowering drugs (Table 3) between patients treated and not treated with adrenalectomy.

When compared with baseline, the prevalence of T2DM increased, whereas the prevalence of impaired glucose tolerance decreased significantly during the follow-up period in patients both with and without adrenalectomy (Table 3). Surgical removal of the adrenal adenoma failed to influence the prevalence of T2DM. At the time of follow-up, there were no statistically significant differences in the concentrations of plasma glucose, in the frequencies of usage of antidiabetic agents (Table 3), between patients treated and not treated with adrenalectomy.

When compared with the data obtained from a large cohort representing the Hungarian general population (31), the prevalences of hypertension and diabetes mellitus were significantly higher in patients with NFAAs both at baseline (Table 4) and at the time of follow-up (Table 5). These prevalences were significantly increased also in patients treated with surgery when compared with the general population (data not shown).

The number of various atherosclerotic events, as well as the number of coronary and peripheral arterial interventions occurring after the diagnosis of NFAA and adrenalectomy in the surgical group is presented in Table 6. No statistically significant differences were found in the prevalences of these events and interventions between patients treated and not treated with adrenalectomy. In addition, the cardiovascular mortality was also similar in the groups of patients treated and not treated with adrenalectomy.

Thirteen of the 125 patients (10.4\%) with NFAAs qualified for subclinical Cushing's syndrome, of which two patients fulfilled both criteria. Midnight plasma cortisol concentrations but not those measured at $0800 \mathrm{~h}$ or after a low-dose dexamethasone test were significantly higher in patients with subclinical Cushing's syndrome when compared with those found in patients without subclinical Cushing's syndrome (Table 7). Five of the 13 patients with subclinical Cushing's syndrome were treated with surgery. Mean tumor diameter in all patients with subclinical Cushing's syndrome and in those who were operated on did not differ from that found in patients without subclinical Cushing's syndrome. In addition, the occurrence of metabolic and cardiovascular risk factors was similar in patients with and without subclinical Cushing's syndrome. One of the patients diagnosed initially with subclinical Cushing's syndrome developed suppressed plasma ACTH concentration at follow-up without any signs and symptoms of hypercortisolism. No other major changes were detected in any of the laboratory parameters of these patients at the followup visit. There were no significant differences in any other laboratory parameters or in the prevalences of incident vascular events and interventions between patients with and without subclinical Cushing's syndrome (not shown in tables).

\section{Discussion}

The long-term benefit attained from surgical intervention is one of the most important unresolved issues regarding the management of patients with incidentally discovered adrenal tumors. Patients with adrenal masses causing unambiguous hormonal overactivity and those with suspected malignancy are clearly candidates for surgical interventions. Although the prevalence of metabolic abnormalities and accompanying disorders resulting in an increased atherosclerotic risk are high among patients with NFAAs and especially in those causing subclinical hypercortisolism $(15,16)$, the cause and effect relationship between 


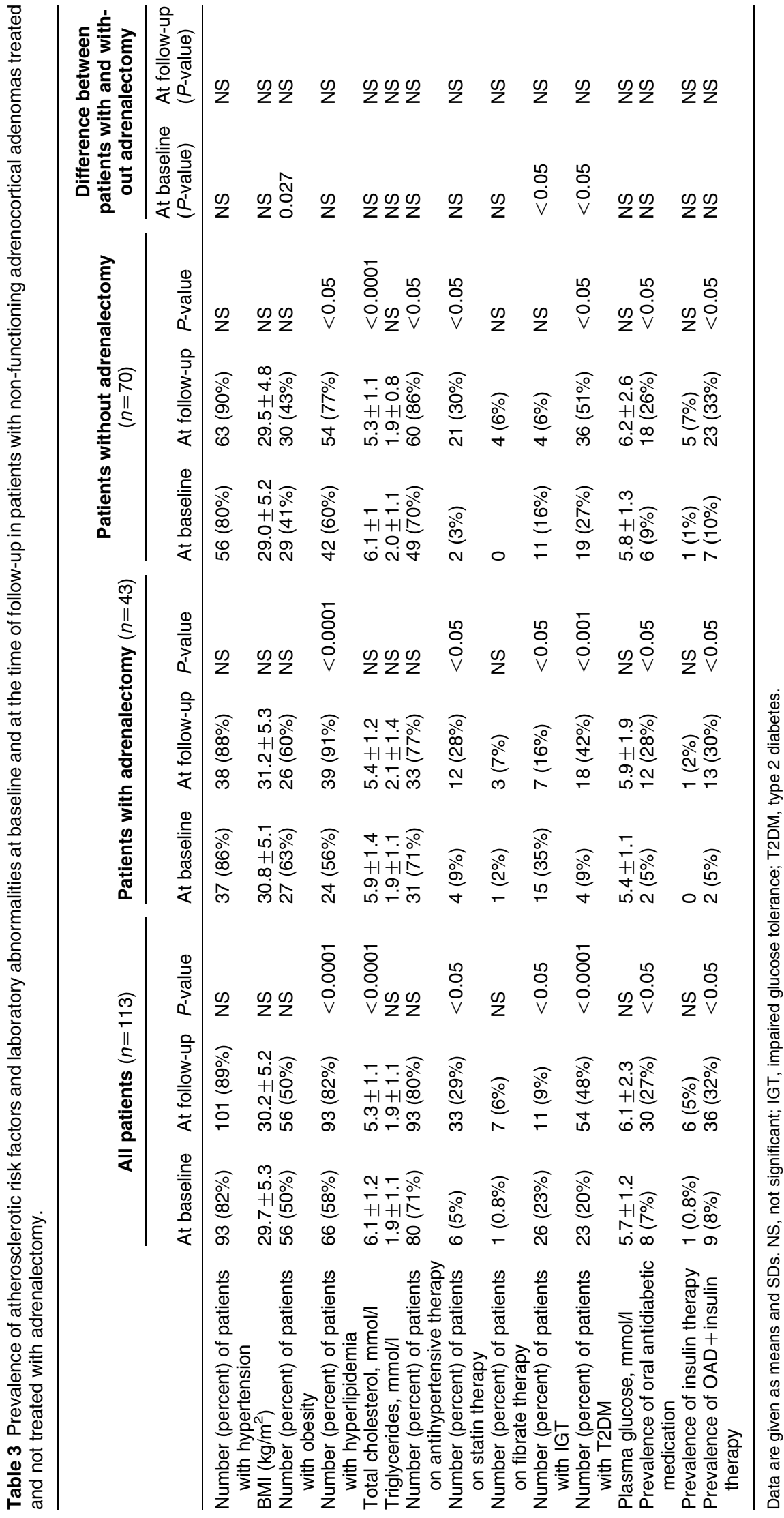


Table 4 Prevalences of high blood pressure and type 2 diabetes mellitus in patients with non-functioning adrenocortical adenomas at baseline and in the general Hungarian population.

\begin{tabular}{|c|c|c|c|c|c|c|}
\hline \multirow[b]{2}{*}{ Sex } & \multicolumn{2}{|c|}{$\begin{array}{l}\text { Patients with non-functioning } \\
\text { adrenocortical adenomas } \\
\text { at baseline }\end{array}$} & \multicolumn{2}{|c|}{ General Hungarian population } & \multicolumn{2}{|c|}{$\begin{array}{c}\text { Difference between patients with } \\
\text { non-functioning adrenocortical } \\
\text { adenoma and general Hungarian } \\
\text { population }\end{array}$} \\
\hline & Females & Males & Females & Males & Females & Males \\
\hline $\begin{array}{c}\text { Number of } \\
\text { patients }\end{array}$ & 89 & 24 & 23000 & 22079 & & \\
\hline $\begin{array}{l}\text { Mean age of } \\
\text { patients, year }\end{array}$ & 50.8 & 53.4 & & & & \\
\hline Age range, year & & & $45-54$ & $45-54$ & & \\
\hline $\begin{array}{l}\text { Number (percent) } \\
\text { of patients with } \\
\text { hypertension }\end{array}$ & $72(81 \%)$ & $21(87 \%)$ & $6184(27 \%)$ & $5877(27 \%)$ & $P<0.0001$ & $P<0.0001$ \\
\hline $\begin{array}{l}\text { Number (percent) } \\
\text { of patients with } \\
\text { type } 2 \text { diabetes }\end{array}$ & $16(18 \%)$ & 7 (29\%) & $982(4 \%)$ & $1595(7 \%)$ & $P<0.0001$ & $P<0.0001$ \\
\hline
\end{tabular}

adrenal adenoma and increased atherosclerotic risk has not been clearly established.

Our present study, in accordance with other reports (18), demonstrates that the prevalences of several ARF are increased in patients with NFAAs. At the time of diagnosis, the prevalences of hypertension, T2DM, obesity, and hyperlipidemia in our patients were comparable with those reported in the majority of other series $(6,10,16-18,21-26,32)$. Among several clinical, biochemical, and hormonal parameters investigated in our study, adrenal tumor diameter was the only parameter influencing significantly the decision between surgical and non-surgical treatment of our patients with NFAAs.

It is presently unclear how surgical removal of NFAAs may affect the increased atherosclerotic risk of these patients. The few follow-up studies of patients with nonfunctioning adrenal tumors have been focused on the prevalence of growth of tumor mass or change in hormonal activity (33-36), but the prevalence of various cardiovascular events has not been evaluated in these patients. It has been shown that the atherosclerotic risk decreases, but not returns to normal after the cure of overt (28) and subclinical Cushing's syndrome (27). However, only a few studies investigated the postoperative changes in various clinical and metabolic parameters reflecting atherosclerotic risk in patients with non-functioning adrenal tumors $(18,22)$. Insulin resistance has been shown to be improved in some, but not all patients after unilateral adrenalectomy in patients with non-functioning adrenal tumors including those presenting with subclinical hypercortisolism (21).

When comparing patients with and without adrenalectomy, detailed investigations of various plasma lipoprotein fractions, basal plasma glucose, serum

Table 5 Prevalences of hypertension and type 2 diabetes mellitus in patients with non-functioning adrenocortical adenomas without adrenalectomy at the time of follow-up and in the general Hungarian population.

\begin{tabular}{|c|c|c|c|c|c|c|}
\hline \multirow[b]{2}{*}{ Sex } & \multicolumn{2}{|c|}{$\begin{array}{l}\text { Patients with non-functioning } \\
\text { adrenocortical adenomas without } \\
\text { adrenalectomy at the time of } \\
\text { follow-up }\end{array}$} & \multicolumn{2}{|c|}{ General Hungarian population } & \multicolumn{2}{|c|}{$\begin{array}{l}\text { Difference between patients with } \\
\text { non-functioning adrenocortical } \\
\text { adenomas without adrenalectomy } \\
\text { at the time of follow-up and general } \\
\text { Hungarian population }\end{array}$} \\
\hline & Females & Males & Females & Males & Females & Males \\
\hline $\begin{array}{c}\text { Number of } \\
\text { patients }\end{array}$ & 53 & 17 & 19799 & 16691 & & \\
\hline $\begin{array}{l}\text { Mean age of } \\
\text { patients (year) }\end{array}$ & 60.5 & 63.2 & & & & \\
\hline Age range (year) & & & $55-64$ & $55-64$ & & \\
\hline $\begin{array}{l}\text { Number (percent) } \\
\text { of patients with } \\
\text { hypertension }\end{array}$ & $47(89 \%)$ & $16(94 \%)$ & $9716(49 \%)$ & 7414 (44\%) & $P<0.0001$ & $P<0.0001$ \\
\hline $\begin{array}{l}\text { Number (percent) } \\
\text { of patients with } \\
\text { type } 2 \text { diabetes } \\
\text { mellitus }\end{array}$ & $25(47 \%)$ & $11(65 \%)$ & $2082(11 \%)$ & $2347(14 \%)$ & $P<0.0001$ & $P<0.0001$ \\
\hline
\end{tabular}


Table 6 Cardiovascular/cerebrovascular morbidity and mortality at the time of follow-up in patients with non-functioning adrenocortical adenomas treated and not treated with adrenalectomy.

\begin{tabular}{llll}
\hline & $\begin{array}{l}\text { Patients with } \\
\text { adrenalectomy } \\
(n=47)\end{array}$ & $\begin{array}{l}\text { Patients without } \\
\text { adrenalectomy } \\
(n=78)\end{array}$ & $\begin{array}{l}\text { Difference between } \\
\text { patients with and without } \\
\text { adrenalectomy }(P \text { value) }\end{array}$ \\
\hline $\begin{array}{l}\text { Number (percent) of patients with } \\
\text { cardiovascular morbidity }\end{array}$ & $16(34 \%)$ & $25(32 \%)$ & 0.8 \\
$\begin{array}{l}\text { Number (percent) of major } \\
\text { cardiovascular events }\end{array}$ & $9(19 \%)$ & $13(17 \%)$ & 0.7 \\
$\begin{array}{l}\text { Number (percent) of patients with } \\
\text { angina pectoris }\end{array}$ & $7(15 \%)$ & $9(12 \%)$ & 0.58 \\
$\begin{array}{l}\text { Number (percent) of patients with } \\
\text { acute myocardial infarction }\end{array}$ & $2(4 \%)$ & $9(12 \%)$ & 0.16 \\
$\begin{array}{l}\text { Number (percent) of } \\
\text { cardiovascular mortality }\end{array}$ & $2(4 \%)$ & $3(4 \%)$ & 0.9 \\
$\begin{array}{l}\text { Number (percent) of patients with } \\
\text { coronary interventions }\end{array}$ & $1(2 \%)$ & $6(8 \%)$ & 0.2 \\
$\begin{array}{l}\text { Number (percent) of patients with } \\
\text { percutaneous transluminal coronary } \\
\text { angioplasty }\end{array}$ & $1(2 \%)$ & $3(4 \%)$ & 0.6 \\
$\begin{array}{l}\text { Number (percent) of patients with } \\
\text { coronary bypass surgery }\end{array}$ & 0 & $4(5 \%)$ & 0.1 \\
$\begin{array}{l}\text { Number (percent) of intervention for } \\
\text { peripheral arterial stenosis/occlusion }\end{array}$ & $7(15 \%)$ & $5(6 \%)$ & 0.1 \\
$\begin{array}{l}\text { Number (percent) of patients with } \\
\text { cerebrovascular stroke }\end{array}$ & $7(15 \%)$ & $12(15 \%)$ & 0.9 \\
\hline
\end{tabular}

insulin, and C-peptide concentrations did not indicate any metabolic benefit from the surgical removal of NFAAs. This finding was in accordance with the lack of differences in the prevalences of cardiovascular adverse events and vascular interventions between patients with and without adrenalectomy. Among several parameters investigated in the present study, plasma total cholesterol was the only ARF, which showed a decrease at the time of follow-up, but this change proved to be independent of adrenal surgery and could be related to the more frequent usage of lipid-lowering agents, especially statins, at the time of follow-up.

To our best knowledge, this is the first study in patients with NFAAs, which investigated not only the

Table 7 Baseline hormonal findings in patients with non-functioning adrenocortical adenomas with and without subclinical Cushing's syndrome.

\begin{tabular}{cccc}
\hline & $\begin{array}{c}\text { Patients } \\
\text { without } \\
\text { SCS }\end{array}$ & $\begin{array}{c}\text { Patients } \\
\text { with SCS }\end{array}$ & $\begin{array}{c}\text { Difference } \\
\text { between } \\
\text { patients with } \\
\text { and without } \\
\text { SCS }\end{array}$ \\
\hline $\begin{array}{c}\text { Midnight plasma } \\
\text { cortisol }(\mu \mathrm{g} / \mathrm{dl})\end{array}$ & $2.4 \pm 1.4$ & $6.0 \pm 3.9$ & $<0.05$ \\
$\begin{array}{c}\text { Morning plasma } \\
\text { cortisol }(\mu \mathrm{g} / \mathrm{dl})\end{array}$ & $10.4 \pm 5.2$ & $11.6 \pm 5.1$ & $\mathrm{NS}$ \\
$\begin{array}{c}\text { Plasma cortisol } \\
\text { after low-dose } \\
\text { DXM ( } \mu \mathrm{g} / \mathrm{dl})\end{array}$ & $1.8 \pm 0.7$ & $3.1 \pm 3.0$ & $\mathrm{NS}$ \\
$\begin{array}{c}\text { Plasma ACTH } \\
(\mathrm{pg} / \mathrm{ml})\end{array}$ & $26.1 \pm 16.8$ & $21.2 \pm 14.7$ & $\mathrm{NS}$ \\
\hline
\end{tabular}

Data are given as means and SDs. SCS, subclinical Cushing's syndrome; NS, not significant. baseline atherosclerotic risk profile and its short-term change after adrenalectomy, but also the prevalence of long-term adverse cardiovascular events. Most importantly, our results indicate that despite the highly increased atherosclerotic risk parameters, surgical removal of the non-functioning adrenal adenoma failed to lower the prevalence of various adverse vascular events.

Our present study has some important limitations which should be taken into account. It is important to note that the prevalence of hypertension in our patients with NFAA was very high even at baseline $(80 \%)$. The most probable explanation for this observation is that in several cases, ultrasonography or computer tomography were performed preferably in hypertensive patients to search for secondary causes of high blood pressure. The relatively low number of patients, especially the low number of patients with subclinical Cushing's syndrome represents another important limitation of our study. However, the long follow-up period should be considered as a strength of the study which may, at least partially, compensate for the relatively small patient cohort. Further limitations are the retrospective nature of this study and the lack of usage of standardized drug treatment protocol. However, the medical treatment of the patients during the follow-up period was managed mainly by the patients' general practitioners according to the general treatment practices. Our analysis revealed an absence of significant differences in the usage of various drug treatments between patients treated and not treated with adrenalectomy. Nevertheless, we cannot exclude the possibility of minor differences, 
for example, in the intensities of various drug treatments or in the compliance of these patients.

Our observations support the possibility that the association between NFAAs and the high prevalence of adverse atherosclerotic risk profile does not necessarily reflect a cause and effect relationship, as these metabolic abnormalities may persist for a long period of time after surgical removal of the NFAAs. It is possible that the lack of improvement of adverse atherosclerotic risk profile after adrenal surgery may be the consequence of persisting abdominal obesity and insulin resistance, similar to those observed during a long-term follow-up of patients after curative surgery for pituitary Cushing's disease (28).

In conclusion, our results clearly indicate that adrenalectomy performed in patients with non-functioning adrenocortical adenomas failed to normalize or improve the adverse metabolic profile and the increased prevalence of hypertension, T2DM, dyslipidemia, and obesity during a 9-year period of postoperative followup. Adrenalectomy in these patients did not result in a decrease of atherosclerotic morbidity and mortality. Nevertheless, a large prospective, randomized study may be needed to explore more definitively the longterm outcome of adrenalectomy on adverse metabolic profile as well as on atherosclerotic mortality and morbidity in these patients. This prospective trial should focus also on the differences in the long-term consequences of adrenocortical adenomas with and without the laboratory abnormalities of subclinical Cushing's syndrome.

\section{Declaration of interest}

The authors declare that there is no conflict of interest that would prejudice the impartiality of this scientific work.

\section{Funding}

This work was supported by grants from the Hungarian Scientific Research Fund (OTKA K73267) and from the Ministry of Health (ETT 090/2006).

\section{Acknowledgements}

We thank Dr Zoltán Vokó (University of Debrecen, Hungary) for statistical advice.

\section{References}

1 Copeland DM. The incidentally discovered adrenal mass. Annals of Internal Medicine 198398 940-945.

2 Milton MD, Gross MD \& Shapiro B. Clinically silent adrenal masses. Journal of Clinical Endocrinology and Metabolism 199377 885-889.

$3 \mathrm{NIH}$. State-of-the-science statement on management of the clinically inapparent adrenal mass ('incidentaloma'). NIH Consensus and State-of-the-Science Statements 200219 1-23.

4 Seppel T \& Schlaghecke R. Subclinical hypercorticolism in incidentally detected adrenal adenoma. Deutsche Medizinische Wochenschrift 1996121 503-507.
5 McLeod MK, Thompson NW, Gross MD, Bardeson AG \& Bardeson L. Sub-clinical Cushing's syndrome in patients with adrenal incidentalomas. Pitfalls in diagnosis and management. The American Surgeon 199056 398-403.

6 Terzolo M, Osella G, Alí A, Boretta G, Cesario F, Pacotti P \& Angeli A. Subclinical Cushing's syndrome in adrenal incidentaloma. Clinical Endocrinology $1998 \mathbf{4 8}$ 89-97.

7 Luton JP, Martinez M, Coste J \& Berthrat J. Outcome in patients with adrenal incidentaloma selected for surgery: analysis of 88 cases investigated in a single clinical center. European Journal of Endocrinology 2000143 111-117.

8 Tsagarakis S, Kokkoris P, Roboti C, Malagari C, Kaskarelis J, Vlassopoulou V, Alevizaki C \& Thalassinos N. The low-dose dexamethasone suppression test in patients with adrenal incidentalomas: comparisons with clinically euadrenal subjects and patients with Cushing's syndrome. Clinical Endocrinology 199848 627-633.

9 Caplan RH, Strutt PJ \& Wickus GG. Subclinical hormone secretion by incidentally discovered adrenal masses. Archives of Surgery 1994129 291-296.

10 Mantero F, Terzolo M, Arnaldi G, Osella G, Masini AM, Alí A, Giovagnetti M, Opocher G \& Angeli A. A survey on adrenal incidentaloma in Italy, Study group on adrenal tumors of the Italian society of endocrinology. Journal of Clinical Endocrinology and Metabolism 200085 637-644.

11 Terzolo M, Osella G, Alí A, Boretta G, Magro GP, Termine A, Pacotti P \& Angeli A. Different patterns of steroid secretion in patients with adrenal incidentaloma. Journal of Clinical Endocrinology and Metabolism $1996 \mathbf{8 1}$ 740-744.

12 Tanabe A, Naruse M, Nishikawa T, Yoshimoto T, Shimizu T, Seki T, Takagi S, Imaki T \& Takano K. Autonomy of cortisol secretion in clinically silent adrenal incidentaloma. Hormone and Metabolic Research 200133 444-450.

13 Tsagarakis S, Vassiliadi D \& Thalassinos N. Endogenous subclinical hypercortisolism: Diagnostic uncertainties and clinical implications. Journal of Endocrinological Investigation 2006 29 471-482.

14 Shen WT, Lee J, Kebebew E, Clark OH \& Duh QY. Selective use of steroid replacement after adrenalectomy: lessons from 331 consecutive cases. Archives of Surgery 2006141 771-774.

15 Tauchmanovà L, Rossi R, Biondi B, Pulcrano M, Nuzzo V, Palmieri EA, Fazio S \& Lombardi G. Patients with subclinical Cushing's syndrome due to adrenal adenoma have increased cardiovascular risk. Journal of Clinical Endocrinology and Metabolism $2002874872-4878$.

16 Terzolo M, Pia A, Alí A \& Osella G. Adrenal incidentaloma: a new cause of the metabolic syndrome? Journal of Clinical Endocrinology and Metabolism 200287 998-1003.

17 Leibowitz G, Tsur A, Chayen SD, Salameh M, Raz I, Cerasi E \& Gross DJ. Preclinical Cushing's syndrome: an unexpected frequent cause of poor glycaemic control in obese diabetic patients. Clinical Endocrinology 199644 717-722.

18 Rossi R, Tauchmanova L, Luciano A, Di Martino M, Battista C, Del Viscovo L, Nuzzo V \& Lombardi G. Subclinical Cushing's syndrome in patients with adrenal incidentaloma: clinical and biochemical features. Journal of Clinical Endocrinology and Metabolism $2000 \mathbf{8 5}$ 1440-1448.

19 Vierhapper H, Heinze G, Gessl A \& Exner M. Adrenocortical tumors: prevalence of impaired glucose tolerance and of 'Paradoxal rise' of cortisol during an oral glucose tolerance test. Experimental and Clinical Endocrinology and Diabetes $2003 \mathbf{1 1 1}$ $415-420$.

20 Garappa GG, Pantanetti P, Arnaldi G, Mantero F \& Faloia E. Body composition and metabolic features in women with adrenal incidentaloma or Cushing's syndrome. Journal of Clinical Endocrinology and Metabolism 200186 5301-5306.

21 Midorikawa S, Sanada H, Hashimoto S, Suzuki T \& Watanabe T. The improvement of insulin resistance in patients with adrenal incidentaloma by surgical resection. Clinical Endocrinology 2001 $\mathbf{5 4} 797-804$.

22 Bernini G, Moretti A, Lacconi P, Miccoli P, Nami R, Lucani B \& Salvetti A. Anthropometric, haemodynamic, humoral and 
hormonal evaluation in patients with incidental adrenocortical adenomas before and after surgery. European Journal of Endocrinology 2003148 213-219.

23 Reincke M, Nieke J, Krestin GP, Saeger W, Allolio B \& Winkelmann W. Preclinical Cushing's syndrome in adrenal 'incidentalomas': comparison with adrenal Cushing's syndrome. Journal of Clinical Endocrinology and Metabolism 199275 826-832.

24 Fernandez-Real JM, Ricart EN, Simo R, Salinas I \& Webb SM. Study of glucose tolerance in consecutive patients harbouring incidental adrenal tumors. Clinical Endocrinology 199849 53-61.

25 Lazúrová I, Dudásová D, Wagnerová H, Dravecká I \& Petrásová D. Adrenal incidentalomas and the metabolic syndrome - are there any differences between adenoma and hyperplasia? Neoplasma 200653 324-327.

26 Terzolo M, Bovio S, Pia A, Conton PA, Reimondo G, Dall'Asta C, Bemporad D, Angeli A, Opocher G, Mannelli M, Ambrosi B \& Mantero F. Midnight serum cortisol as a marker of increased cardiovascular risk in patients with a clinically inapparent adrenal adenoma. European Journal of Endocrinology 2005153 307-315.

27 Erbil Y, Ademoglu E, Özbey N, Barbaros U, Tulumoglu Yanik B, Salmaslioglu A, Bozbora A \& Özarmagan S. Evaulation of the cardiovascular risk in patients with subclinical Cushing syndrome before and after surgery. World Journal of Surgery 2006301665 1671.

28 Colao A, Pivonello R, Spiezia S, Faggiano A, Ferone D, Filippella M, Marzullo P, Cerbone G, Siciliani M \& Lombardi G. Persistence of increased cardiovascular risk in patients with Cushing's disease after five years of successful cure. Journal of Clinical Endocrinology and Metabolism $1999 \mathbf{8 4} 2664-2672$.

29 Bennett PH. Impact of the new WHO classification and diagnostic criteria. Diabetes, Obesity and Metabolism 19991 1-6.
30 Chobanian AV, Bakris GL, Black HR, Cushman WC, Green LA, Izzo JL Jr, Jones DW, Materson BJ, Oparil S, Wright JT Jr \& Roccella EJ. Seventh report of the joint national committee on prevention, detection, evaluation, and treatment of high blood pressure. Hypertension 200342 1206-1252.

31 Széles G, Vokó Z, Jenei T, Kardos L, Pozsai Z, Bajtay A, Papp E, Pásti G, Kósa Zs, Molnár I, Lun K \& Ádány R. A preliminary evaluation of a health monitoring prgramme in Hungary. European Journal of Public Health 200515 26-32.

32 Reincke M, Fassnacht M, Väth S, Mora P \& Allolio B. Adrenal incidentalomas: a manifestation of the metabolic syndrome? Endocrine Research 199622 757-761.

33 Sirén J, Tervahartiala P, Sivula A \& Haapaiainen R. Natural course of adrenal incidentalomas: seven-year follow-up study. World Journal of Surgery 200024 579-582.

34 Barzon L, Scaroni C, Sonino N, Fallo F, Paoletta A \& Boscaro M. Risk factors and long-term follow-up of adrenal incidentalomas. Journal of Clinical Endocrinology and Metabolism $199984520-526$.

35 Libè R, Dall'Asta C, Barbetta L, Baccarelli A, Beck-Peccoz P \& Ambrosi B. Long-term follow-up study of patients with adrenal incidentalomas. European Journal of Endocrinology $2002 \mathbf{1 4 7}$ 489-494.

36 Bülow B, Jansson S, Juhlin C, Steen L, Thorén M, Wahrenberg H, Valdemarsson S, Wängberg B \& Ahrén B. Adrenal incidentaloma follow-up results from a Swedish prospective study. European Journal of Endocrinology 2006154 419-423.

Received 16 January 2009

Accepted 23 January 2009 